\title{
The Relationship Between Physical Fitness and School Performance
}

\author{
Jamie A. Donnelly \\ Walden University
}

Past research has indicated a significant relationship between physical fitness and standardized test scores; however, the relationship between physical fitness and other aspects of school performance has yet to be empirically examined in a population specifically composed of middle school girls. Because girls have a harder time transitioning through the middle school years, they are an important group to study in this context. This study examined several factors that contribute to school success, such as classroom behavior, attendance, and grades, in relation to physical fitness among a group of adolescent girls. It was specifically designed to examine the statistical relationship between physical fitness, as measured by the FitnessGram, and quantitative data on school performance including grades, standardized test scores, school behavior, and attendance among 280 middle school girls. The biopsychosocial theory was used as the basis of this study, with the biological factors of fitness levels and body mass index, psychological factors of grades and test scores, and social factors of attendance and behavior. A one-way between-subjects multivariate analysis of variance demonstrated that the psychological and social factors of school performance were significantly related to the biological factor of physical fitness. A statistically significant correlation was also found between body mass index, grades, and attendance. Interventions to increase physical fitness may be a way to foster greater school performance in middle school girls.

Keywords: academics, behavior, physical fitness, attendance, middle school

\section{Introduction}

Seventeen percent of children and adolescents in the United States are obese, causing them to develop adult diseases such as heart disease, diabetes, and high cholesterol while still in childhood, in addition to cancer and respiratory disorders (Cecchini et al., 2010; Centers for Disease Control, 2014;). However, the effects of obesity on children go beyond the physical diseases that can develop from being obese. For example, obesity has significant social consequences such as bullying, social isolation, and low self-esteem that result from the child's weight. There is a documented connection between obesity in adolescence and low self-esteem, with higher incidences of poor psychosocial adjustment, depression, and suicide (Robinson, 2006). Because of these factors, obese adolescents are more likely than nonobese peers to be victims of teasing and bullying by peers. Children's overall health status significantly affects their school performance and future success (Story, Nanney, \& Schwartz, 2009). When children are not healthy, it is difficult for them to focus or attend school. Therefore, it is important to identify ways to keep children in good physical health using methods such as fitness habits and nutrition, so that they perform to their highest capacity in school.

This research was originally conducted as part of a doctoral dissertation, under the direction of Dr. Patti Barrows. 
The social, psychological, and medical consequences of obesity make it an important topic to address with children and adolescents. Home, school, and community can work together to combat obesity. However, collaboration is important so children and adolescents receive the same messages no matter where they are. Schools are responsible for educating children on a variety of topics, including health and wellness (Raffaele Mendez, Young, Mihalas, Cusumano, \& Hoffman, 2006). Therefore, schools are a good place to start educating on the benefits of health and wellness, especially if the lessons are not being taught at home.

School success is integral for children's overall success and is impacted by factors such as grades, attendance, behavior, and academic achievement scores. Childhood obesity has been negatively associated with academic achievement, while physical fitness has been positively associated with academic achievement, as measured by standardized test scores (London \& Castrechini, 2011). Edwards, Mauch, and Winkelman (2011) found that good nutritional practices, increased physical activity, and high levels of physical fitness were associated with high standardized math scores, while high standardized reading scores were associated with nutritional practices and increased physical activity in a sample of sixth graders. Similarly, Chomitz et al.'s (2009) examination of the relationship between Massachusetts Comprehensive Assessment System (MCAS) test scores and physical fitness found that the odds of passing the MCAS math and English tests increased with the number of fitness tests (out of 5) that were also passed.

The transition through the middle school years tends to be more difficult on girls than on boys (Grills-Taquechel, Norton, \& Ollendick, 2010; Rice, Frederickson, \& Seymour, 2011). London and Castrechini (2011) found larger disparities on both math and language arts test scores in girls than in boys when examining their fitness trajectories. This longitudinal study was designed to discover the relationship between obesity, fitness, and academic achievement in middle school students utilizing standardized test scores. London and Castrechini also found a positive relationship between physical fitness and academic performance. However, while the rates of academics were consistent overtime between fit and unfit students, there was a discrepancy between them at the initial measurement. As they continue down a trajectory of consistently fit or unfit, the differences in test scores are more evident in girls than in boys (London \& Castrechini, 2011). These results indicated that while there was a positive relationship between fitness and academics, any differences were more pronounced for girls than for boys. Examining the fitness data from seventh grade to ninth grade, boys were more likely than girls to go from failing to passing 2 years later, while $69.4 \%$ of girls went from passing to failing in those 2 years. Consequently, girls who consistently pass the fitness tests are likely to score higher on the math and English tests (London \& Castrechini, 2011).

According to the Association for Applied Sport Psychology (2011), psychological benefits are evident from physical activity. These include improved mood, self-esteem, body image, and confidence in physical abilities; reduced stress and the ability to cope with stress; pride in physical accomplishments and satisfaction with self; increased feelings of energy; and decreased depressive symptoms. By examining the relationships between school performance and physical fitness, the social and psychological factors associated with school performance will be linked to the physical aspect of what makes a student ready to perform in the school setting, following the biopsychosocial model.

Physical activity also can have a positive effect on cognitive functioning (Ganzer \& Zauderer, 2011). One example of a physical intervention is the use of exergames. These videogames with exercise 
components such as Wii, Dance Dance Revolution, and EyeToy have been shown to increase physical activity in youth and are also being used as part of the physical education curriculum in some school districts (Staiano \& Calvert, 2011). Exergames increase several cognitive skills, which, in turn, have the tendency to increase academic performance. Staiano and Calvert cited a study by Etnier, Nowell, Landers, and Sibley (2006) stating "A meta-analysis documented that physical activity enhanced cognitive performance among adolescents, including improved perceptual skills, intelligence quotient, achievement scores, verbal tests, mathematics tests, and developmental level, and academic readiness" (p. 96). Exergames are a creative and fun way to work on cognitive skills that will be critical to school success.

Children who engage in more "active play," meaning they engage in unstructured playing in their free time, have overall higher physical activity levels than those who engage in less active play (Brockman, Jago, \& Fox, 2010). In addition, the more time spent using media, such as television, computer, and videos, the less committed children are to physical activity (Racine, DeBate, Gabriel, \& High, 2011). By encouraging active play in the children's free time and less sedentary activities, parents can encourage their children to be more active overall. School recess is an opportunity to provide children with active play time. Playspace and equipment may help to increase moderate and vigorous activity among children at recess (Ridgers, Fairclough, \& Stratton, 2010) and afterschool programs focused on physical activity rather than sedentary activities may increase self-esteem and commitment to physical activity (Racine et al., 2011). Story et al. (2009) found that schools are making progress in implementing interventions for healthier lifestyles. It comes down to policies to enforce healthier eating and the increase of physical activity in the school setting. Schools are integral in teaching life skills, such as nutrition and exercise, and may be the only source of exercise for some students (Willette, 2007).

With all the research touting the benefits of physical fitness on adolescents and the research outlining the factors that contribute to a student's success in middle school, it would be wise to explore the impact of physical fitness on school performance, especially in relation to an adolescent's transition to middle school. Edwards et al. (2011) discovered that in the area of math, higher academic scores were found in those who had better nutritional practices and increased physical activity. Likewise, in the area of reading, higher academic scores correlated to higher levels of physical activity and better nutritional practices. The researchers suggested that schools examine the time they dedicate to physical activity and nutrition to increase academic performance, through wellness policies and increased opportunities (Edwards et al., 2011). Also examining standardized test scores, Chomitz et al. (2009) concluded that there was a positive, significant relationship between MCAS scores and physical fitness, generalizing to academic achievement and fitness levels. They relay this relationship to motivation, physical health status, increase in concentration, and improvements in self-esteem and mental health.

Similarly, Wittberg, Northrup, and Cottrell (2009) compared academic achievement to each specific test of the FitnessGram to determine which tests had a more significant relationship with each area of academic achievement. They found that aerobic capacity and abdominal strength were significantly related to overall achievement scores. Wittberg, Cottrell, Davis, and Northrup (2010) examined fitness thresholds and their relationship to academic achievement in a sample of fifth graders. They found positive correlations between girls' Pacer results and standardized test scores and boys' mile run results and standardized test scores. Wittberg et al. (2010) further explained the 
need for schools to increase opportunities for physical activity during school, not only for an increase in academic achievement, but for a decrease in health factors, specifically obesity.

In Texas, due to the obesity epidemic in that state, all students in kindergarten through Grade 8 must be provided physical activity and have fitness levels tested in Grades 3 through 12 (Robert Wood Johnson Foundation, 2010). Van Dusen, Kelder, Kohl, Ranjit, and Perry (2011) compared fitness levels using the FitnessGram test to standardized academic testing measured by the Texas Assessment of Knowledge and Skills in students in Grades 3-11. They found a strong, significant relationship between test scores and fitness levels, especially in late middle to early high school students. Body mass index (BMI) did not significantly relate to academics. Van Dusen et al. (2011) recommend physical education mandates in those early adolescent years to enhance physical fitness, and, therefore, enhance academic test scores in students. Also in Texas, the Robert Wood Johnson Foundation (2010) reported results from the Texas Youth Fitness Study which found that there were correlations between fitness, academic achievement, and attendance.

Moving a step further, Blom, Alvarez, Zhang, and Kolbo (2011) examined factors beyond standardized tests in students in grades 3-8 in Mississippi. In addition to finding a positive correlation between physical fitness levels as measured by the FitnessGram and academic achievement scores as measured by the Mississippi state testing, they found that absences decreased as physical fitness levels increased. However, Blom et al. (2011) did not find a relationship between physical fitness levels and the number of disciplinary actions a student had in school. Their findings on attendance show that another factor of school success that could be impacted by physical fitness levels. While several studies have shown the positive correlation between physical fitness and academic achievement, few have examined the factor of attendance, which is important to a student's success.

While it has been found that physical fitness has a positive correlation with standardized test scores (Chomitz et al., 2009; Edwards et al., 2011; London \& Castrechini, 2011), the current study examined its relationship to other areas of school performance, thereby discovering another factor that can help improve the educational experience of middle school girls, who tend to have a difficult transition through middle childhood/early adolescence. Utilizing the biopsychosocial model, which states that health (mental and physical) is an interaction between biological, psychological, and social forces (Pilgrim, 2002; Suls \& Rothman, 2004), the current study examined school performance (psychological and social) in respect to physical fitness (biological). Previous research has determined the relationship between physical fitness levels and standardized test scores, specifically reading and math. However, the research has not explored the relationships between other factors impacting school success, such as behavior, attendance, and grades. As middle school is a difficult time of transition for all students, finding factors that may contribute to school success is essential.

\section{Method}

\section{Participants}

The participants of this study consisted of a convenience sample of female public middle school students from a Grade 6-8 school in Florida. At the time of this study, the school had approximately 1,079 students ( $50 \%$ female and $50 \%$ males), of which $42.72 \%$ receive free/reduced lunch, $10.01 \%$ are eligible for special education services, and $2.04 \%$ are speakers of other languages. The principal of 
the school and the school district's department of research and accountability granted permission to conduct the study. The study included data from all 280 female students who participated in the FitnessGram assessment through their physical education class in the 2013-2014 school year. The students' ages ranged from 12 to 16 years old, with a mean age of 13.12 years old. The students ranged from Grades 6 to 8, with $46.5 \%$ in Grade 6, 31.3\% in Grade 7, and 22.2\% in Grade 8.

Sample size was determined through an a priori power analysis using GPower 3.1.7 (Faul, Erdfelder, Lang, \& Buchner, 2007). The results of the power analysis showed that the study required a sample of at least 192 participants; my use of 280 subjects, the number of subjects whose data I had access to, increased reliability by significantly exceeding the minimum sample size.

\section{Procedures}

FitnessGram data (zone classification based on scores from the FitnessGram assessment's cardiovascular measure) and school performance data (Florida Comprehensive Achievement Test [FCAT] test scores, grade point average (GPA), number of absences, number of disciplinary referrals, and conduct grades) were obtained through the school district's research and accountability department. The students were not engaged in anything different than what they would normally have done during the course of their general curriculums.

The reliability data and validity data for the FitnessGram was assessed through various studies. The reliability coefficients for the Pacer test, the test with which the students' physical fitness was measured, were above .64. Concurrent validity of the Pacer is high in samples of adolescent females, ranging from .69 to .90. This information can be found in the FitnessGram reference guide (Plowman $\&$ Meredith, 2013). Because the FitnessGram is a series of tests, each test has its own validity and reliability data. Both reliability and validity are high and acceptable for all tests. Previous tests assessing aerobic capacity yielded reliability coefficients from .60 to .90 (Boileau, Bonen, Heyward, \& Massey, 1977; Cureton, 1976; Safrit, 1990), with the most reliable results from children over the age of 10 years old. Validity for tests of aerobic capacity range from .60 to .84 (Plowman \& Meredith, 2013). These are considered acceptable levels of validity.

More recent studies have led researchers to further examine the psychometric properties of the FitnessGram, based on data collected by teachers in a typical school setting. The Texas Youth Evaluation Project researchers gathered the psychometric information, by allowing physical education teachers across the state of Texas to administer and accumulate the data from their students (Morrow, Martin, \& Jackson, 2010). The researchers examined interrater reliability between pairs of teachers (teacher/teacher reliability) and between pairs of experts of the FitnessGram (expert/expert reliability). Teacher/teacher reliability was highest for measures of BMI (>.90), reliable for cardiorespiratory fitness (>.80), and less reliable for musculoskeletal fitness (>.70). The expert/expert reliability measures yielded similar results. In response to measures of validity, teacher/teacher validity was similar to expert/expert validity. In addition, result patterns were similar with BMI, and cardiorespiratory fitness validities were higher than musculoskeletal measures (Morrow et al., 2010). With high reliability and validity data, and comparable data between teacher/teacher pairs and expert/expert pairs, the teachers can be reliable sources for assessing fitness levels using the FitnessGram for the use of schoolwide studies. 
Overall, reliability for the various FitnessGram tests is high, while validity varies across tests (Plow man \& Meredith, 2013). The FitnessGram reference guide states that assessing validity is difficult in many cases, and needs to be studied further. However, having teachers assess the students does not impact the reliability or validity of the data, and can be considered an appropriate source of information when gathering data from this instrument.

The teachers administering the FitnessGram to the students in the current study were observed on a few occasions by this researcher and followed the guidelines in the FitnessGram manual (Plowman \& Meredith, 2013). They also had several years of experience in administering and scoring the FitnessGram to middle school students.

I obtained approval from Walden University's Institutional Review Board through the application process. I also followed the Assessment, Accountability, and Research office of the school district's application process to conduct research within the district.

\section{Research Design}

This study employed a quantitative research design using multivariate analysis of variance to find the relationship between variables. I sought to determine the statistical positive relationship between physical fitness, as measured by the FitnessGram, and school performance. The criterion variables are the fitness levels on the FitnessGram, needs improvement zone (NIZ), healthy fitness zone (HFZ), and above healthy fitness zone (AHFZ). The outcome measures are school grades, school attendance, school behavior, and standardized test scores (FCAT). The measures of the variables in this study, with one independent variable (fitness level) and the multiple dependent variables (DV; school performance) allow for the data to be analyzed through MANOVA. The research questions and the hypotheses reflect this type of analysis. MANOVA analyses were used to determine if there are relationships between categorical criterion variables and multiple, correlated outcome measures and to determine if the various levels of physical fitness can predict school performance.

Using Statistical Package for Social Sciences (IBM SPSS 21), separate analyses were run for each measure of school performance compared to the fitness level as measured by the FitnessGram tests. The analyses determined if a significant relationship exists, and the nature of that relationship. MANOVA analyses were conducted to predict the students' school performance (academic grades, behavior grades, discipline referrals, attendance [number of days absent], and FCAT scores) based on their levels of physical fitness.

\section{Results}

A one-way between-subjects MANOVA was conducted to assess the effects of three fitness zones on school performance. This employed six DVs that measured various aspects of school performance (FCAT reading scores, FCAT math scores, absences, GPA, discipline referrals, and conduct grade average) and the independent variable, fitness level. The overall means, standard deviations, and intercorrelation for the six DVs are presented in Tables 1 and 2. 
Table 1. Means and Standard Deviations for Dependent Variables

\begin{tabular}{lcc}
\hline School Performance Measure & $M$ & $S D$ \\
\hline Absences & 9.26 & 7.86 \\
Grade point average & 3.33 & 0.68 \\
Conduct grade average & 2.64 & 0.39 \\
FCAT reading score & 3.08 & 1.20 \\
FCAT math score & 2.63 & 1.16 \\
Referrals & 1.15 & 3.64 \\
\hline
\end{tabular}

Table 2. Intercorrelations of Dependent Variables

\begin{tabular}{|c|c|c|c|c|c|}
\hline School Performance Measure & 2 & 3 & 4 & 5 & 6 \\
\hline 1. Absences & $-.305^{* *}$ & $-.162 * *$ & $-.132 * *$ & $-.182^{* *}$ & $.225^{* *}$ \\
\hline 2. Grade point average & & $.603^{* *}$ & $.552^{* *}$ & $.629^{* *}$ & $-.483^{* *}$ \\
\hline 3. Conduct grade average & & & $.387 * *$ & $.405^{* *}$ & $-.569 * *$ \\
\hline 4. FCAT reading score & & & & $.715^{* *}$ & $-.247 * *$ \\
\hline 5. FCAT math score & & & & & $-.253^{*}$ \\
\hline 6. Referrals & & & & & \\
\hline
\end{tabular}

${ }^{*} p<.05 .{ }^{* *} p<.01$.

Because the intercorrelations between the DVs were statistically significant $(p<.05)$, the use of MANOVA to reduce the Type I error rate was justified. Table 3 presents the means and standard deviations for the DVs, broken down by fitness zone.

Table 3. School Performance Measure Means and Standard Errors by Fitness Zone

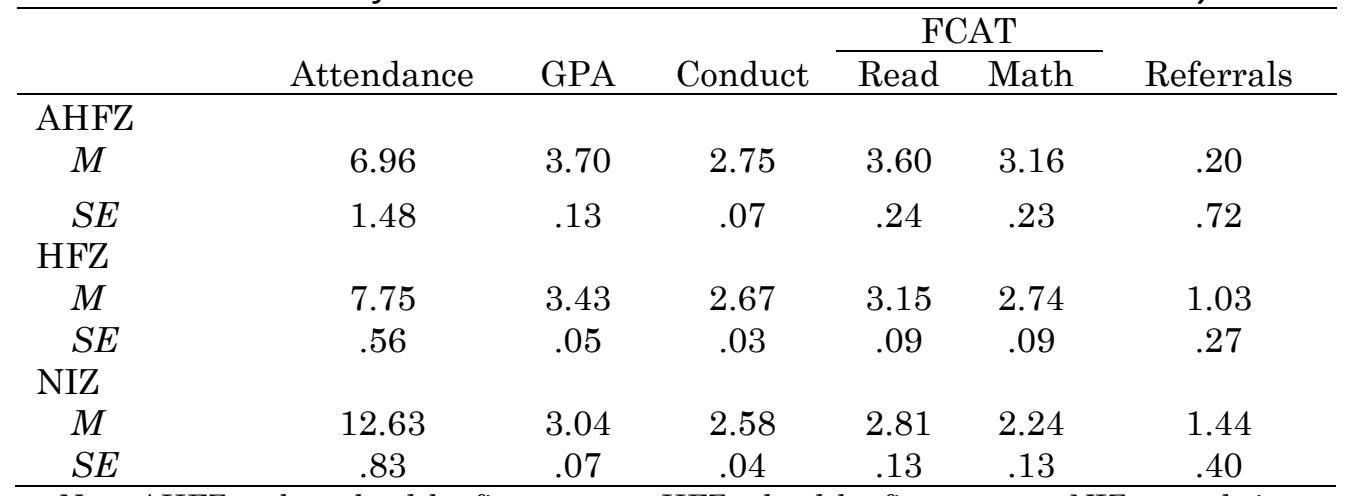

Note. AHFZ = above healthy fitness zone; HFZ = healthy fitness zone; NIZ = needs improvement zone; GPA = grade point average; FCAT $=$ Florida Comprehensive Achievement Test.

Using the Wilks' criterion, the combined DVs were significantly affected by fitness zone, Wilks $\lambda=$ $.019, F(6,272)=2,282, p<.001$. The results indicated a strong association between fitness zone and the combined DVs measuring school performance, and accounted for approximately $98 \%$ of the variability in the combined DVs $(1-\lambda=.98)$. Table 4 depicts the Univariate analysis of variance results. 
Table 4. Univariate Analyses of Variance for the Effects of Fitness Zone

\begin{tabular}{lcccc}
\hline Variable & $d f$ & $F$ & $p$ & $\eta^{2} \mathrm{p}$ \\
\hline Attendance & 2 & 12.96 & $<.001$ & .09 \\
Grade point average & 2 & 14.6 & $<.001$ & .095 \\
Conduct & 2 & 2.5 & .085 & .018 \\
FCAT reading & 2 & 4.7 & $<.01$ & .033 \\
FCAT math & 2 & 8.3 & $<.001$ & .056 \\
Referrals & 2 & 1.2 & .314 & .008 \\
\hline
\end{tabular}

Note. FCAT= Florida Comprehensive Achievement Test.

Univariate analyses of variance for the effects of fitness zone on GPA, FCAT reading, FCAT math, and absences revealed statistical significance. Discipline referrals and conduct grade average were not significant. Using Bonferroni's adjustment to determine alpha level, significance was reached at $p=.008$. GPA $(M=3.33,95 \%$ confidence interval [CI] [3.25, 3.41]); FCAT math $(M=2.63,95 \%$ CI $[2.49,2.76])$; and absences $(M=9.26,95 \%$ CI $[8.36,10.15])$ were all significant at the .008 alpha level. FCAT reading $(M=3.08,95 \%$ CI [2.94, 3.22], $p=.01)$ was just below the significance level. Conduct grade average $(M=2.64,95 \%$ CI $[2.59,2.68], p=.085)$ and discipline referrals $(M=1.15$, $95 \%$ CI $[.74,1.57], p=.314$ ) were not significant. GPA, FCAT math, and absences had more significant effect sizes than did FCAT reading conduct grade average, and discipline referrals.

Post hoc mean comparison tests (Bonferroni) for the measures of school performance showed that absences in the NIZ ( $M=12.63)$ were statistically significantly higher than those in the HFZ ( $M=$ $7.75)$ and those in the AHFZ $(M=6.96)$. GPA in the NIZ $(M=3.04)$ were statistically significantly lower than those in the HFZ $(M=3.43)$ and those in the AHFZ $(M=3.70)$. FCAT math scores in the NIZ $(M=2.24)$ were statistically significantly lower than those in the HFZ $(M=2.74)$ and those in the AHFZ $(M=3.16)$. FCAT reading scores in the NIZ $(M=2.81)$ were statistically significantly lower than those in the AHFZ $(M=3.60)$. No statistically significant results were found for conduct grades or discipline referrals. Results of the post hoc test are shown in Table 5.

The MANOVA analyses supported the hypotheses that middle school girls with higher physical fitness levels would have higher GPAs, better attendance, and higher standardized test scores. The analysis did not support the hypothesis that middle school girls with higher physical fitness levels would have fewer behavior concerns. Correlational analyses were conducted to test the hypothesis that middle school girls who are at a healthy weight, as measured by BMI, will demonstrate a better school performance. Students with a healthy BMI demonstrated better grades $(r=.207 ; p<.01)$ and attendance $(r=-.121 ; p=.046)$ than those with a higher BMI. There was no significant correlation between BMI and behavior or standardized test scores. 
Table 5. Bonferroni Post-Hoc Comparisons

\begin{tabular}{|c|c|c|c|c|c|}
\hline Dependent & & & Mean & & \\
\hline Variable & Zone (I) & Zone (J) & Difference & $S E$ & $p$ \\
\hline Absences & NIZ & HFZ & 4.871 & 1.001 & $<.001$ \\
\hline & & AHFZ & 5.665 & 1.699 & .003 \\
\hline & $\mathrm{HFZ}$ & NIZ & -4.871 & 1.001 & $<.001$ \\
\hline & & AHFZ & .794 & 1.586 & 1.000 \\
\hline GPA & NIZ & HFZ & -.390 & .086 & $<.001$ \\
\hline & & AHFZ & -.663 & .146 & $<.001$ \\
\hline & $\mathrm{HFZ}$ & NIZ & .390 & .086 & $<.001$ \\
\hline & & AHFZ & -.273 & .137 & .140 \\
\hline Conduct & NIZ & HFZ & -.085 & .050 & .265 \\
\hline & & AHFZ & -.169 & .084 & .139 \\
\hline & $\mathrm{HFZ}$ & NIZ & .085 & .050 & .265 \\
\hline & & AHFZ & -.084 & .079 & .865 \\
\hline FCAT Read & NIZ & $\mathrm{HFZ}$ & -.342 & .160 & .102 \\
\hline & & AHFZ & -.788 & .272 & .012 \\
\hline & $\mathrm{HFZ}$ & NIZ & .342 & .160 & .102 \\
\hline & & AHFZ & -.446 & .254 & .241 \\
\hline FCAT Math & NIZ & HFZ & -.500 & .153 & .004 \\
\hline & & AHFZ & -.923 & .260 & .001 \\
\hline & $\mathrm{HFZ}$ & NIZ & .500 & .153 & .004 \\
\hline & & AHFZ & -.423 & .243 & .249 \\
\hline Referrals & NIZ & HFZ & .41 & .485 & 1.00 \\
\hline & & AHFZ & 1.24 & .823 & .402 \\
\hline & $\mathrm{HFZ}$ & NIZ & -.41 & .485 & 1.00 \\
\hline & & AHFZ & .83 & .768 & .845 \\
\hline
\end{tabular}

Note. AHFZ = above healthy fitness zone; HFZ = healthy fitness zone; NIZ = needs improvement zone; GPA = grade point average FCAT $=$ Florida Comprehensive Achievement Test.

\section{Discussion}

The purpose of this study was to examine the statistical relationship between levels of physical fitness as measured by the FitnessGram and school performance, utilizing quantitative data derived from grades, standardized test scores, school behavior, and attendance within a sample of 280 middle school girls. The study identified a significant relationship between the combined variables of school performance and physical fitness. This study's findings specifically demonstrated a significant association between fitness levels and grades, standardized test scores, and attendance. There was no significant relationship between fitness levels and behavior measured using conduct grades and discipline referrals. Also, a significant negative correlation was found between BMI and school performance. In combination, these findings suggest that physical fitness is an important factor in middle school girls' transition into and throughout middle school, as there is an overall, positive relationship between fitness levels and school performance.

The findings of this study confirmed the results of several previously conducted studies (Carlson et al., 2008; Chomitz et al., 2009; Edwards et al., 2011; Hollar et al., 2010; Van Dusen et al., 2011), which examined the relationship between physical fitness and standardized test scores. Students in 
the HFZ and AHFZ had higher scores on the FCAT math tests than those in the NIZ. Those students who scored in the AHFZ had significantly higher FCAT reading scores than those in the NIZ.

Bass, Brown, Laurson, and Coleman (2013) also found significant relationships between physical fitness and reading and math scores for both middle school girls and boys. In Bass et al. (2013), boys and girls in the HFZ were more likely to pass math and reading exams, as measured by the Illinois Standards Achievement Test. Bass et al. specifically found that, when examining aerobic fitness and muscular endurance, these relationships were consistent even when controlling for socioeconomic status. Further research by Srikanth, Petrie, Greenleaf, and Martin (2015) compared boys to girls and found no differences. Srikanth et al. (2015) found that cardiorespiratory fitness levels were positively related to state math and reading scores in both girls and boys in middle school. Students' self-reports of physical activity were related directly to higher levels of cardiorespiratory fitness (Srikanth et al., 2015). Future studies can examine the relationships of school performance and physical fitness in both genders, comparing the results for boys and girls.

Previous studies generally did not consider other factors of school performance such as attendance and behavior that were investigated in this study. The present study found that physical fitness levels had a significant relationship with attendance; better physical fitness was associated with fewer absences. Specifically, the number of absences was significantly higher for those students in the NIZ than for those in the HFZ or the AHFZ. When students are in school more often, they are more likely to perform better academically. The findings in the current study confirmed results of studies by the Robert Wood Johnson Foundation (2010); Blom et al. (2011); and Telles, Singh, Bhhardwaj, Kumar, and Balkrishna (2013), which found significant relationships between physical fitness and attendance. High physical fitness levels and physical activity participation are positively related to attendance and should be taken into account when schools examine ways to increase the percentage of students in school on a regular basis.

The current study revealed no significant relationship between behavior and physical fitness levels, in terms of the number of office discipline referrals and conduct grades. Whether a student was physically fit or not, their behavior remained consistent. However, there was little variation in behavior in this study. There were very few students in the sample who had discipline referrals, and even those that did had a very low number of referrals. This lack of variation may have caused the insignificant findings. Similar to the results of the current study, Blom et al. (2011) failed to find a relationship between physical fitness levels and number of disciplinary actions in students.

Academic achievement was investigated through the relationship between physical fitness levels and GPA. GPAs for students in the NIZ were significantly lower than those in the HFZ and those in the AHFZ. GPA reflects, not only ability, but the work effort a student puts in to academics on a daily basis. The findings indicate that students who are more physically fit have better GPAs, and perform better on academic work on an everyday basis. Utilizing a self-report of physical activity, Fox, BarrAnderson, Neumark-Sztainer, and Wall (2010) found that physical activity and sports team participation in high school girls were associated with a higher GPA. For middle school students, positive relationship between physical activity and GPA only existed when factoring in participation on a sports team. Unfortunately, the emphasis is shifting away from physical activity in schools to focus on the core academic subjects that are evaluated for high-stakes testing. Also, budgetary constraints are either removing physical education class from the curriculum or having untrained, and sometimes unwilling, elementary education classroom teachers be the primary instructors of 
physical education (Sherman, Tran, \& Alves, 2010). Taking away physical education to give more time to core academic subjects does not increase grades in the core academic subjects (Trudeau \& Shephard, 2008). Furthermore, physical activity was related positively to concentration, memory, and classroom behavior (Trudeau \& Shephard, 2008).

The current study found a significant relationship between BMI and school performance, as measured by grades and attendance; no significant relationship between BMI and behavior or standardized test scores was revealed. Students who are at a healthier weight tend to get better grades and attend school regularly. As previously mentioned, behavior does not appear to be related to physical fitness, and likewise, not related to BMI. Behavior was a limitation in the study due to lack of variability in the data. BMI is also not related to standardized test scores; academic ability remains consistent no matter what the student's weight is. Interestingly, past research found mixed results. No significant relationship was reported between BMI and reading scores through a bivariate model; however was a positive significant predictor of reading achievement when other variables were included (Srikanth et al., 2015). Nevertheless, BMI can be an important factor in the mental health of adolescents. Robinson (2006) made the connection between obesity in adolescence and low self-esteem, poor psychosocial adjustment, depression, and suicide. In addition, other research has found that overweight or obese students may engage in risky behaviors more than healthy-weight students (Farhat, Iannotti, \& Simons-Morton, 2010). In summary, the BMI and school performance measures relationship is an area which requires further research.

There were limitations to this study, including the cross-sectional design. Studies with this design are difficult to determine the time element, the time between exposure and outcome. The FitnessGram data is collected at a given point in time and is not an overall measure of performance over time. In addition, there was sampling bias in this study, as the sample came from one middle school and is not representative of all middle school girls. Response bias could arise if some students refused to participate in the FitnessGram assessment. While it is a required part of the physical education curriculum, there may be students who are defiant and will refuse to participate or who are chronically absent and are not in attendance the days that the assessment is being conducted.

Continuing to research these areas can help guide interventions in the school setting, and further, the community, to help children and adolescents reach their full potential. With middle school being a difficult time for many children and adolescents, professionals within the school system should be finding ways to make it less difficult on all students. Adding an emphasis on physical fitness in the school setting could be that change to ease the transition for middle school girls.

\section{References}

Association for Applied Sport Psychology. (2011). Psychological benefits of exercise. Retrieved from http://appliedsportpsych.org/resource-center/health-and-fitness/articles/psych-benefits-ofexercise

Bass, R., Brown, D., Laurson, K., \& Coleman, M. (2013). Physical fitness and academic performance in middle school students. Acta Paediatrica, 102, 832-837. doi:10.1111/apa.12278

Blom, L., Alvarez, J., Zhang, L., \& Kolbo, J. (2011). Associations between health-related physical fitness, academic achievement, and selected academic behaviors of elementary and middle school students in the state of Mississippi. ICHPER-SD Journal of Research, 6, 13-19. 
Boileau, R. A., Bonen, A., Heyward, V. H., \& Massey, B. H. (1977). Maximum aerobic capacity on the treadmill and bicycle ergometer of boys 11-14 years of age. Journal of Sports Medicine, 17, $153-162$.

Brockman, R., Jago, R., \& Fox, K. (2010). The contribution of active play to the physical activity of primary school children. Preventative Medicine, 51, 144-147.

Carlson, S., Fulton, J., Lee, S., Maynard, L., Brown, D., Kohl, H., \& Dietz, W. (2008). Physical education and academic achievement in elementary school: Data from the Early Childhood Longitudinal Study. American Journal of Public Health, 98, 721-727. doi:10.2105/AJPH.2007.117176

Cecchini, M., Sassi, F., Lauer, J., Lee, Y., Guajardo-Barron, V., \& Chisholm, D. (2010). Tackling of unhealthy diets, physical inactivity, and obesity: health effects and cost-effectiveness. Lancet, 376, 1775-1784. doi:10.1016/S0140-6736(10)61514-0

Centers for Disease Control. (2014). Obesity rates among all children in the United States. Retrieved from http://www.cdc.gov/obesity/data/childhood.html

Chomitz, V., Slining, M., McGowan, R., Mitchell, S., Dawson, G., \& Hacker, K. (2009). Is there a relationship between physical fitness and academic achievement? Positive results from public school children in the northeastern United States. Journal of School Health, 79, 3037. doi:10.1111/j.1746-1561.2008.00371.x

Cureton, K. J. (1976). Determinants of running and walking endurance performance in children: Analysis of a path model (Unpublished doctoral dissertation). University of Illinois at Urbana-Champaign, Champaign, IL.

Edwards, J., Mauch, L., \& Winkelman, M. (2011). Relationship of nutrition and physical activity behaviors and fitness measures to academic performance for sixth graders in a Midwest city school district. Journal of School Health, 81, 65-73. doi:10.1111/j.1746-1561.2010.00562.x

Etnier, J., Nowell, P., Landers, D., \& Sibley, B. (2006). A meta-regression to examine the relationship between aerobic fitness and cognitive performance. Brain Research Reviews, 52, 119-130. http://doi.org/10.1016/j.brainresrev.2006.01.002

Farhat, T., Iannotti, R., \& Simons-Morton, B. (2010). Overweight, obesity, youth, and health-risk behaviors. American Journal of Preventative Medicine, 38, 258-267. doi:10.1016/j.amepre.2009.10.038

Faul, F., Erdfelder, E., Lang, A. G., \& Buchner, A. (2007). G*Power 3: A flexible statistical power analysis for the social, behavioral, and biomedical sciences. Behavior Research Methods, 39, 175-191. doi:10.3758/BF03193146

Fox, C., Barr-Anderson, D., Neumark-Sztainer, D., \& Wall, M. (2010). Physical activity and sports team participation: Associations with academic outcomes in middle school and high school students. Journal of School Health, 80, 31-37. doi:10.1111/j.1746-1561.2009.00454.x

Ganzer, C., \& Zauderer, C. (2011). Promoting a brain-healthy lifestyle. Nursing Older People, 23, 2427. doi:10.7748/nop2011.09.23.7.24.c8679

Grills-Taquechel, A., Norton, P., \& Ollendick, T. (2010). A longitudinal examination of factors predicting anxiety during the transition to middle school. Anxiety, Stress, \& Coping, 23, 493513. doi:10.1080/10615800903494127 
Hollar, D., Messiah, S., Lopez-Mitnik, G., Hollar, T., Almon, M., \& Agatston, A. (2010). Effect of a two-year obesity prevention intervention on percentile changes in body mass index and academic performance in low-income elementary school children. American Journal of Public Health, 100, 646-652. doi:10.2105/AJPH.2009.165746

London, R., \& Castrechini, S. (2011). A longitudinal examination of the link between youth physical fitness and academic achievement. Journal of School Health, 81, 400-408. doi:10.1111/j.1746-1561.2011.00608.x

Morrow, J., Martin, S., \& Jackson, A. (2010). Reliability and validity of the FITNESSGRAM: Quality of teacher-collected health-related fitness surveillance data. Research Quarterly for Exercise and Sport, 81, S24-S30. doi:10.1080/02701367.2010.10599691

Pilgrim, D. (2002). The biopsychosocial model in Anglo-American psychiatry: Past, present and future? Journal of Mental Health, 11, 585-594. doi:10.1080/09638230020023930

Plowman, S. A., \& Meredith, M. D. (Eds.). (2013). FitnessGram/ActivityGram reference guide (4th Edition). Dallas, TX: The Cooper Institute. Retrieved from https://www.cooperinstitute.org/vault/2440/web/files/662.pdf

Racine, E., DeBate, R., Gabriel, K., \& High, R. (2011). The relationship between media use and psychological and physical assets among third- to fifth- grade girls. Journal of School Health, 81, 749-755. doi:10.1111/j.1746-1561.2011.00654.x

Raffaele Mendez, L., Young, E., Mihalas, S., Cusumano, D., \& Hoffman, L. (2006). What teachers can do to reduce hidden stressors for girls in middle school? Middle School Journal, 38, 13-22.

Rice, F., Frederickson, N., \& Seymour, J. (2011). Assessing pupil concerns about transition to secondary school. British Journal of Educational Psychology, 81, 244-263. doi:10.1348/000709910X519333

Ridgers, N., Fairclough, S., \& Stratton, G. (2010). Variables associated with children's physical activity levels during recess: The A-CLASS project. International Journal of Behavioral Nutrition and Physical Activity, 7, 74-81. doi:10.1186/1479-5868-7-74

Robert Wood Johnson Foundation. (2010). The Texas Youth Fitness Study. Research Quarterly for Exercise and Sport, 81, 1-9.

Robinson, S. (2006). Victimization of obese adolescents. The Journal of School Nursing, 22, 201-206. doi:10.1177/10598405050220040301

Safrit, M. J. (1990). The validity and reliability of fitness tests for children: A review. Pediatric Exercise Science, 2, 9-28. doi:10.1123/pes.2.1.9

Sherman, C., Tran, C., \& Alves, Y. (2010). Elementary school classroom teacher delivered physical education: Costs, benefits, and barriers. Physical Educator, 67, 2-17.

Srikanth, S., Petrie, T., Greenleaf, C., \& Martin, S. (2015). The relationship of physical fitness, selfbeliefs, and social support to the academic performance of middle school boys and girls. Journal of Early Adolescence, 35, 353-377. doi:10.1177/0272431614530807

Staiano, A., \& Calvert, S. (2011). Exergames for physical education courses: Physical, social, and cognitive benefits. Child Development Perspectives, 5, 93-98. doi:10.1111/j.17508606.2011.00162.x 
Story, M., Nanney, M., \& Schwartz, M. (2009). Schools and obesity prevention: Creating school environments and policies to promote healthy eating and physical activity. The Milbank Quarterly, 87, 71-100. doi:10.1111/j.1468-0009.2009.00548.x

Suls, J., \& Rothman, A. (2004). Evolution of the biopsychosocial model: Prospects and challenges for health psychology. Health Psychology, 23, 119-125. doi:10.1037/0278-6133.23.2.119

Telles, S., Singh, N., Bhardwaj, A., Kumar, A., \& Balkrishna, A. (2013). Effect of yoga or physical exercise on physical, cognitive, and emotional measures in children: A randomized controlled trial. Child and Adolescent Psychiatry and Mental Health, 7, 37. doi:10.1186/1753-2000-7-37

Trudeau, F. \& Shephard, R. (2008). Physical education, school physical activity, school sports and academic performance. International Journal of Behavioral Nutrition and Physical Activity, 5, 1-12. doi:10.1186/1479-5868-5-10

Van Dusen, D., Kelder, S., Kohl, H., Ranjit, N., \& Perry, C. (2011). Associations of physical fitness and academic performance among schoolchildren. Journal of School Health, 81, 733-740. doi:10.1111/j.1746-1561.2011.00652.x

Willette, A. (2007). Where have all the parents gone? Do efforts to regulate food advertising to curb childhood obesity pass constitutional muster? The Journal of Legal Medicine, 28, 561-577. doi:10.1080/01947640701732189

Wittberg, R., Cottrell, L., Davis, C., \& Northrup, K. (2010). Aerobic fitness thresholds associated with fifth grade academic achievement. American Journal of Health Education, 41, 284-291.

Wittberg, R., Northrup, K., \& Cottrell, L. (2009). Children's physical fitness and academic performance. American Journal of Health Education, 40, 30-36.

The Journal of Social, Behavioral, and Health Sciences is an open-access, peer-reviewed, online interdisciplinary journal focusing on research findings that address contemporary national and international issues. Its objectives are to (a) encourage dialogue between scholars and practitioners in the social, behavioral, and health sciences that fosters the integration of research with practice; (b) promote innovative models of interdisciplinary collaboration among the social, behavioral, and health sciences that address complex social problems; and (c) inform the relationship between practice and research in the social, behavioral, and health sciences.

Walden University Publishing: http://www.publishing.waldenu.edu 